\title{
A MORTE CHEGA PARA TODOS: O RECRUDESCIMENTO DO CAPITALISMO NO FIM DO SÉCULO XX
}

\author{
Charles Albuquerque Ponte* \\ Maria Bevenuta Sales de Andrade**
}

\begin{abstract}
Resumo: $O$ objetivo desse trabalho é o de discutir a modificação discursiva do início da década de 1990, após a queda do bloco comunista e o surgimento de apologias à vitória do capitalismo, a partir da transformação ocorrida nas formas de representação dos monstros filmicos. Para isso, apresenta-se, primeiramente, o discurso apologético ao capitalismo de Francis Fukuyama (1992), com a finalidade de se cotejar a maneira como o monstro Jason Vorhees, da série Sexta-feira 13 (1981; 1982; 1984), e da Morte em Premonição (2000), são elaborados, afetando também as reações de suas vítimas. A constatação principal do texto é que, ao final da análise, a ubiquidade, naturalidade e inevitabilidade do assassino da década de 1990 apresentam-se em consonância com a vitória do capital professada por Fukuyama, assinalando um derrotismo exacerbado.
\end{abstract}

Palavras-chave: Cinema Slasher. Teoria Crítica. Capitalismo.

Um dos diferenciais mais marcantes do gótico ao longo de sua existência, em grande parte responsável pela recepção bem sucedida por diversos segmentos da arte ao longo dos séculos, é sua capacidade de dialogar com seu contexto de produção, narrativizando-o em busca de uma parcial compreensão das mudanças. O paralelo pode ser traçado, especialmente, ao interpretar a principal personagem característica do gênero, a ameaça frequentemente monstruosa e sobrenatural ${ }^{1}$, parte marcante das principais obras do gênero e metáfora processual dos perigos percebidos em determinado momento histórico. Para as últimas décadas, um desses grandes períodos de transição ocorreu, sem dúvida, no início da década de 1990, com a queda do bloco comunista na Europa oriental, provocando uma grande comoção de vitória capitalista absoluta, notadamente descrita por Francis Fukuyama (1992) sob o argumento de fim da história ${ }^{2}$, e desencadeando uma série de representações artísticas em busca de sua apreensão narrativa. Assim, o objetivo desse trabalho é o de relacionar a performatividade desse discurso de fim da História à tentativa de metaforização gótica dessa ameaça promovida pelo filme Premonição, dirigido por James Wong, em 2000.

\footnotetext{
* Doutor em Teoria e História Literária pela Universidade Estadual de Campinas (UNICAMP). Professor Adjunto IV da Universidade do Estado do Rio Grande do Norte (UERN). E-mail: ca_ponte@yahoo.com.br.

** Mestre em Letras pela Universidade Federal da Paraíba (UFPB). Professora na Universidade do Estado do Rio Grande do Norte (URN). E-mail: bv_salles@yahoo.com.br.

${ }^{1}$ A não sobrenaturalidade das ameaças, ocorrida, por exemplo, nos romances de Ann Radcliffe, como The mysteries of Udolpho, ainda pode ser bastante esclarecedora da ideologia presente nas obras.

${ }^{2} \mathrm{O}$ chamado fim da História já fora anunciado outras vezes, inclusive por nomes importantes da filosofia como Hegel, mas nunca antes esse argumento havia obtido reações tão inauditas e variadas quanto no momento em que Fukuyama o relançou ( $v$. ANDERSON, 1992).
} 
O capitalismo certamente vem ampliando sistematicamente seu escopo de dominação desde sua origem, adaptando-se de uma maneira ou outra aos diversos contextos que encontrou nos cinco continentes, do exacerbado consumo e descarte de mercadorias, característico da sociedade norte-americana, ao comunismo de mercado chinês. Seu desenvolvimetno, desde a expansão mercantilista dos primeiros séculos da idade moderna, passando pela industrialização do fim do século XVIII, culmina na administração dos inconscientes das pessoas, a ponto de qualquer reação individual às coisas estar de antemão contida no capitalismo multinacional hodierno (JAMESON, 1991, p. 3). Nesse âmbito, o conceito de capital humano desponta como maior indicador dessa transformação mais recente, desencadeando a "possibilidade de reinterpretar em termos econômicos e em termos estritamente econômicos todo um campo que, até então, podia ser considerado, e era de fato considerado, não econômico" (FOUCAULT, 2008, p. 302), ou seja, a possibilidade de reescrever a vida dos indivíduos valendo-se de uma terminologia conceitual pertencente à área mercantil e tornando populares expressões como investir em sua formação ou vender [market] sua imagem. O que parece fora de compasso, aqui, é a naturalização de tal processo de imbricação do capital nas vidas humanas, a falta de estranhamento dessa nova forma de mercantilização, agora voluntária, a partir de um círculo vicioso de consumismo em que cada nova conquista agrega, para usar um termo recorrente nesse discurso, valor à força de trabalho, negociada assim por um custo mais alto e com vistas à potencialização do ritmo de consumo ( $c f$. BAUMAN, 2008).

Dentro desse contexto, não é de estranhar que a suposta vitória do capitalismo sobre seu maior antagonista histórico, propagada por Fukuyama em seu $O$ fim da história e o último homem (1992), tenha sido automaticamente celebrada como a última grande modificação de um século marcado por guerras de grande porte e ditaduras sangrentas. Fukuyama apresenta o argumento de que, com a derrocada do comunismo, a derradeira alternativa possível de contraposição ao capitalismo, a luta de classes e, por consequência, a História, teriam chegado a seu fim. Ele assume a influência de dois teóricos que também se voltaram a essa questão: Hegel, para quem o percurso histórico seria uma positividade que acarretaria na realização da liberdade, e Kojève, cuja argumentação pautava-se na promessa de que um Estado igualitário tinha cambiado para uma "existência social reduzida às rotinas do consumo" (ANDERSON, 1992, 71). Nota-se que essa tese sugere uma visão evolucionista de sociedade, já que a argumentação desconsidera o recrudescimento das teocracias no Oriente Médio, Ásia e África, bem como o aumento da interdependência econômica entre Oriente e Ocidente. Além disso, há, na base desse pensamento, uma flagrante dimensão paternalista, fundada na ideia de que essas nações não capitalistas cedo ou tarde reconhecerão a superioridade do neoliberalismo e evoluirão até esse sistema governamental.

Fukuyama tende a se deixar levar por uma superexcitação do capitalismo de consumo, consequência, pelo menos parcialmente, de um shop craze dos anos Reagan nos Estados Unidos, somado aos primeiros sinais de que uma derrocada completa do bloco comunista estava próxima (o artigo original foi lançado em julho de 1989 e o 
muro de Berlim começou a cair em novembro). A partir desses dois contextos, a construção da argumentação Fukuyama (1992, p. 15-18) aponta o tratamento da produção industrial-científica desses dois sistemas como causa para o vácuo evolutivo que havia se formado entre os polos:

\begin{abstract}
As experiências da União Soviética, da China e de outros países socialistas indicam que, embora as economias centralizadas sejam suficientes para alcançar o nível de industrialização representado pela Europa dos anos 1950, são lamentavelmente inadequadas para criar o que chamamos de economias "pós-industriais" complexas, onde a inovação na informação e na tecnologia desempenha um papel muito mais expressivo. [...] $\mathrm{O}$ que chamamos de "lógica da ciência natural moderna" é, na verdade, uma interpretação econômica da mudança histórica, mudança que (ao contrário de sua variante marxista) conduz ao capitalismo e não ao socialismo, como resultado final. A lógica da ciência natural moderna pode explicar muita coisa sobre nosso mundo: por que nós, os residentes das democracias desenvolvidas, trabalhamos em escritórios, ao invés de lutar para viver da terra, por que pertencemos ao sindicato dos trabalhadores, ou organizações profissionais, ao invés de certos membros de tribos ou clãs, por que obedecemos à autoridade de um poder burocrático, ao invés de obedecer a um sacerdote, por que somos alfabetizados e falamos uma língua nacional comum.
\end{abstract}

Nessa passagem, deve-se apontar duas questões pertinentes para a compreensão dessa evolução neoliberal: a pós-industrialização e, como sua consequência, a instrumentalização da ciência. Em primeiro lugar, nota-se a defesa de uma linearidade evolutiva do capital, de nação mercantilista para industrial, e então para pós-industrial, de modo que somente nações neoliberais estariam aptas a alcançar tais estágios superiores. Isto ocorreria em grande parte devido ao encurtamento da distância entre as nações advindo do desenvolvimento tecnológico. Ou seja, o aumento e crescente importância da área de serviços, através da utilização da comunicação em tempo real promovida pela globalização e pela explosão da internet para dar um salto na logística das relações comerciais, facilitariam assim o acesso à informação em tempo real e o offshoring, como aponta a lista de grandes modificações no funcionamento das empresas a partir da segunda metade da década de 1990 elencada por Friedman (2007). Em segundo lugar, esse último estágio evolutivo só poderia vir a acontecer diante de uma modificação na ciência, que, de acordo com Adorno e Horkheimer (1985), seria cooptada para funcionar como mera ferramenta do capital, sintonizando suas buscas para a produção de commodities que possam ser automaticamente convertidas em produtos, embaladas e comercializadas.

Com base na lógica pós-industrial de ciência instrumentalizada, Fukuyama aduz a caracterização da sociedade contemporânea perfeita a partir de duas conquistas: a possibilidade de realização dos desejos dos indivíduos e pela capacidade de reconhecimento de seus membros, que teriam culminado "convenientemente no mesmo ponto, a democracia liberal capitalista" (FUKUYAMA, 1992, p. 349). Para ele, a sociedade neoliberal oferece promessas de satisfazer os desejos de cada indivíduo, desconsiderando que: 1) somente os desejos de poucos são alcançados em detrimento da opressão de muitos; 2) essa falta nos sujeitos nunca pode ser suprida por completo; e 3) a demanda por objetos de grande tecnologia, como tablets ou smartfones, muitas vezes é forjada a partir de uma autoimagem ilusória de poder, desprovida de nenhuma ou 
pouca necessidade real. Já em relação ao reconhecimento, Fukuyama aponta que ainda há muitos ajustes por fazer no sistema capitalista, mas, ao invés de pensar o que poderia ser feito, prefere argumentar a proximidade nunca vista da realização desse quesito no Estado neoliberal, desqualificando, em paralelo, as tentativas de valoração (ou desvaloração) igualitária de cada indivíduo, como nos Estados comunistas.

Em vista da tese de que os eventos históricos, como guerras e tratados, continuaram a acontecer mesmo depois de anunciado o fim da História, movimentando o seu curso, Fukuyama (1992, p. 374-5) afirma que são simplesmente ajustes locais cuja influência não afeta o mundo como um todo; além disso, segundo Anderson (1992, 83), o próprio Kojève já havia sugerido anteriormente que "o movimento da história está acelerando cada vez mais, mas avançando cada vez menos". O foco aqui, no entanto, independentemente da real possibilidade de haver ou não mais alternativa ao capitalismo neoliberal, ou do número de equívocos que Fukuyama tenha cometido ao descrever seu ponto de vista, não é propriamente a validade do argumento, mas antes pensar um paralelo entre a construção discursiva acerca do fim da História como inevitabilidade, sendo este um dos fatores novos que Fukuyama insere em sua reelaboração e que, por sua vez, produziu tamanha reverberação no meio acadêmico, além de sedimentar as bases da mudança ocorrida no diálogo do gótico com seu meio.

Diante do exposto, após sistematizarmos a elaboração de Fukuyama, a próxima seção trará, através de uma abordagem comparativa, uma descrição das modificações de um filme de terror produzido no fim da década de 1990 (e lançado em 2000), Premonição, verificando como o discurso gótico terminou por adaptar-se a essa espécie de Zeitgeist da inevitabilidade surgida no bojo da derrocada do bloco comunista e como essa mimetização permeia os aspectos formais do filme, especialmente na construção do monstro.

TODOS NA MESMA LISTA

A fim de assegurar uma percepção mais ampla quanto às modificações ocorridas no cinema de horror da década de 1990, em especial no filme Premonição, optamos por comparar a caracterização do monstro Morte com um monstro popular na década de 1980, o Jason Voorhees, da série Sexta-feira $13^{3}$, analisando principalmente a composição visual dos mesmos, a motivação que os leva aos assassinatos, a função que assumem na focalização da narrativa, suas fraquezas e armas; também exploraremos o repertório das vítimas em potencial no que concerne ao enfrentamento desse inimigo, entre a reação e a aceitação passiva.

A princípio, o filme Premonição e a franquia Sexta-feira 13 parecem ter enredos bastante similares, facilitando assim o processo comparativo. Nos dois casos, um grupo de pessoas é perseguido por um assassino, embora nos filmes Sexta feira 13, partes 2, 3 e $4(1981 ; 1982 ; 1984)$, esse conjunto de jovens vai trabalhar em um acampamento de

\footnotetext{
${ }^{3}$ Utilizamos principalmente o segundo, o terceiro e o quarto filmes da série, respectivamente de 1981, 1982 e 1984, os dois primeiros dirigidos por Steve Miner e o terceiro por Joseph Zito. O filme que originou a série foi descartado por ter como assassina a mãe de Jason, a senhora Voorhees.
} 
férias durante o verão, onde Jason Vorhees espera para assassinar todos aqueles que se engajarem em prazeres ilícitos, como o consumo de drogas ou a prática de sexo sem compromisso. Por sua vez, em Premonição (2000), dirigido por James Wong, o grupo de uma mesma escola está prestes a embarcar em um avião para uma excursão à França que, por conta de uma visão de um deles, Alex Chance Browning (Devon Sawa), desiste do voo e assiste à explosão do avião momentos depois; no entanto, uma entidade incorpórea, identificada com a personificação da própria Morte, não contente com o escape das pessoas, começa a persegui-los e matá-los um por um.

A primeira e mais facilmente notável diferença entre os dois monstros está, de fato, na esfera corpórea. Jason, como um simples garoto que retornou da morte na forma de uma máquina de matar sobrenatural, tem um corpo definido, ao contrário da Morte em Premonição, que é quase totalmente incorpórea, sendo simplesmente sugerida na forma de eventos e manifestações naturais. Essa distinção fornece diversos elementos importantes para o cotejo em questão, do qual o primeiro a ser destacado é a proximidade com a sociedade: Jason é um híbrido entre humano e sobre-humano, criado a partir de um momento de negligência dos jovens que cuidavam dele, cujo corpo pode ser ferido, mas nunca eliminado; por outro lado, acerca da Morte, não se pode identificar uma origem ou causa, nem um lado humano ${ }^{4}$, ela age como uma força puramente sobrenatural que sempre existiu e que dita o futuro dos seres.

O que precisa ser apontado em relação à Morte é que, na ausência de um corpo, ela passa a ser personificada por elementos da natureza, predominantemente reflexos de sombras e vento. A implicação dessa caracterização traduz-se no adensamento do caráter ubíquo da morte, já que sombras e correntes de ar estão presentes em todos os lugares, ou, nas palavras da personagem principal Alex Browning, "Sinto como se estivesse nos rodeando sempre", e, assim como o capitalismo de Fukuyama, natural e sem mais alternativas viáveis. O paralelo parece mais concreto ao se considerar que essas sombras não ganham forma naturalmente, uma luz interrompida por um objeto ou corpo, mas antes formam-se como reflexos em superfícies vítreas ou metálicas de objetos de consumo, como se essa ameaça só pudesse se manifestar a partir de produtos industrializados: espelhos, uma chaleira, etc.

As consequências desses aspectos funcionam ideologicamente para iniciar um primeiro mapeamento das modificações discursivas entre os filmes de horror das décadas vizinhas: primeiramente, Jason se apresenta carnal, com um centro corporal, e as vítimas encontram-se em posição de confrontá-lo e combatê-lo diretamente, enquanto a Morte não pode ser enfrentada diretamente por não portar um corpo, ou antes, por corporificar-se de maneira invisível, onipresente e diluída; e, segundo, Jason é descrito como uma criação humana, mesmo que escape ao controle e sempre sobreviva às inúmeras tentativas de exterminá-lo, enquanto a Morte aparenta pertencer a um plano transcendente. Isso pode ser interpretado pelo movimento dialético da unicidade como inexistente: da mesma forma em que, na década de 1980, havia uma alternativa de enfrentamento ao sistema capitalista, essa possibilidade de confronto direto também se encontra presente em relação a um monstro ícone deste decênio; por outro lado, na nova configuração, na década seguinte, uma ameaça que não possui contrapartida ou externalidade se naturaliza automaticamente como incorpórea.

\footnotetext{
${ }^{4}$ Retornaremos abaixo à interpretação do hibridismo em ambos.
} 
A segunda diferença a ser enfatizada apresenta-se na motivação para os assassinatos. O retorno de Jason Vorhees da morte para punir todos aqueles jovens que repetiam as condições de negligência dos primeiros baseia-se em uma espécie de código ético: todas as vezes que algum jovem se entregava a prazeres, geralmente relacionados a sexo e drogas, distraindo-se do trabalho e negligenciando suas obrigações, Jason os punia com a morte; da mesma forma, a heroína que não se engajava em tais prazeres era poupada ao final, apesar de ser levada ao limite. Diante dessa configuração, Jason funcionava como um agente diferenciador para a ética fílmica, ditando o bem e o mal para as personagens e encarregando-se de infligir as punições necessárias.

Em Premonição, a morte segue um padrão menos específico: a primeira fagulha das mortes, a explosão de um avião, não pode ser relacionada a qualquer tipo de causae-efeito, mas antes a um evento caótico sem qualquer lógica aparente. Ademais, o principal mapeador do sistema de loteria da Morte, Alex Browning, parte do princípio de que existe um plano que a priori não pode ser captado, mas somente especulado empiricamente. No filme, logo após o escape do grupo do avião que explodiria momentos depois, a Morte passa a persegui-los e envolvê-los um a um. Nesse sentido, a Morte opera não como agente diferenciador, mas nivelador, despersonalizando os indivíduos e ideologicamente eliminando quaisquer diferenças entre eles; para o sistema da Morte, todos os sujeitos têm o mesmo valor, independente de que posição ocupem.

Claro que, em ambos os filmes, perfiguram imagens baseadas na autoimagem referente à configuração capitalista de cada momento. Para a franquia Sexta-feira 13, o descarte e rápida substituição dos sujeitos a cada episódio permitem uma leitura análoga à esteira de produção fabril, em que cada mão operária realiza apenas uma pequena parte do trabalho de produção, não tendo uma significação individual e podendo ser substituída quase imediatamente por outra, mas cuja permanência encontra-se subordinada a uma aparente lógica de produção. Por outro lado, pode-se então relacionar essa característica da Morte em Premonição ao artigo "The stars down to Earth: the Los Angeles Times astrology column", de Adorno (1994), que compara o sistema de estrelas de Hollywood à astrologia e à crença irracional de que as pessoas estão predestinadas a alguma benesse ou tragédia que lhes chegará de repente sem que precisem fazer qualquer esforço. Adorno (1994, p. 42) afirma que, a partir da incompreensão causada por uma lacuna entre a existência das pessoas e as forças controladoras do sistema, passa-se a acreditar em superstições secundárias irracionais, de forma que "Quem quiser sobreviver sob as condições atuais fica tentado a 'aceitar' estes absurdos, como o veredicto das estrelas[...]". Logo, o advento periódico de benesses que se enquadram neste critério, como a vitória de uma loteria, serviria para incluir um aspecto aparentemente caótico dentro de uma lógica previamente controlada, para causar uma ilusão de que o sistema não é organizado, mas cheio de indeterminações, e que a sorte (ou alguma forma de predestinação ao acaso) pode mudar as condições de existência ${ }^{5}$. Note-se que esse detalhe é reforçado no filme pelo nome da personagem principal, Alex Chance (sorte, ou acaso) Browning.

\footnotetext{
${ }^{5}$ No entanto, para Adorno e Horkheimer (1985, p. 137), mesmo esse acaso é planejado.

PONTE, Charles Albuquerque. ANDRADE, Maria Bevenuta Sales de. A morte chega para todos: o recrudescimento do capitalismo no fim do século XX. Crítica Cultural - Critic, Palhoça, SC, v. 10, n. 1, p. 119131, jan./jun. 2015.
} 
No limite, cada uma dessas opções termina por enfatizar um recalque de seu momento de produção. No primeiro desses períodos, há a necessidade de se reforçar a causalidade do sistema, e, por consequência, asserir que há, sim, uma lógica no capital, implicando que qualquer pessoa possa ser recompensada por seu esforço e propagandeando uma justiça que não existiria no comunismo. Por outro lado, no segundo deles, o recalque é o de que haveria, na falta de uma alternativa a esse sistema, um espaço para o caos em sua própria estrutura, negando a causalidade exacerbada que controlaria as vidas nuas em seus aspectos mais ínfimos.

Por sua vez, na caracterização estética de cada monstro, podemos também escolher outro traço estilístico para representar a centralidade de um corpo: a presença ou ausência de planos subjetivos. No subgênero de horror slasher, um dos clichês visuais mais repetidos é o uso de uma câmera na mão assumindo o ponto-de-vista do monstro, esgueirando-se por entre as árvores e esperando o momento em que as personagens cometam as ações pelas quais serão punidas. $O$ emprego da câmera subjetiva também serve ao propósito de evitar que o espectador não seja exposto precocemente à aparência do monstro, e, logo, a construção dramática do horror não alcance o clímax no início da narrativa; esse recurso pode ser encontrado em todos os filmes da série Sexta-feira $13^{6}$. No caso de Premonição, não há a utilização de planos subjetivos pelo diretor para simular a visão da personagem Morte, o que, aplicando a lógica de sua ubiquidade, reforça o sentimento de que a morte, não podendo ser identificada com um ponto específico de visão, estaria em nenhum lugar e em todos, simultaneamente.

O uso de planos subjetivos, compreendidos aqui como planos nos quais "a câmera assume a posição espacial de uma personagem" (BRANIGAN, 1984, p. 6), assinala um fator interessante na recepção dos filmes: em geral, a personagem que a câmera substitui, somado a outros recursos como a predominância dela na tela, cria um vínculo emocional com a audiência, ou, no bordão de Carol Clover (1992, p. 45), "plano subjetivo [point-of-view] = identificação". A partir desse recurso, é possível constatar uma divisão na focalização dos slashers da década de 1980, entre a personagem feminina que sobrevive ao fim do filme (chamada pela crítica de final girl) e o assassino, de modo que, da mesma forma que é possível encontrar pessoas na plateia torcendo pela vitória dessa heroína, também há aqueles que riem das mortes e desejam que o monstro mate todos os jovens, independentemente de passarem ou não pelo teste de caráter imposto. Isso não acontece em Premonição, porque não há divisão na focalização, o narrador-câmera mostra sua preferência pelos jovens ao tentar escapar da Morte ${ }^{7}$.

A fraqueza de cada monstro é também um aspecto a ser considerado, pois influencia a maneira como as vítimas poderão enfrentá-lo e, dentro do possível, vencê-

\footnotetext{
${ }^{6}$ Convencionou-se, posteriormente, que essa câmera na mão não necessariamente coincide com o olhar escópico do monstro, mas antes indica sua presença na cena, pois os slashers, para aumentar a tensão e o susto nas plateias, passaram a dissimular a visão do assassino, que vê de certo ponto e ataca de surpresa de outro, inesperado.

${ }^{7}$ Contra o argumento de que o desejo de fuga da morte é universal e que o sentimento de impossibilidade atinge a todos, pode-se afirmar que o cinema, com seu caráter potencialmente onírico, frequentemente convence as plateias de que a morte pode, sim, ser vencida.
} 
lo. Jason, sendo corpóreo, sofre parcialmente a fragilidade deste corpo: ele pode ser atacado e ferido como um ser humano comum, de modo que as cicatrizes recebidas nos filmes da série permanecem nas sequências, mesmo que ele, dado por morto, retorne e continue a matar. Outra aparente limitação corpórea consiste em sua falta de agilidade, pois um dos clichês do gênero é o monstro que anda e se move lentamente, mas sempre alcança e mata suas vítimas. Considerando seus motivos para os assassinatos, no entanto, chega-se à percepção da verdadeira fraqueza de Jason, o cumprimento da lei, que permite a vigilância constante, ou seja, quando as heroínas dos filmes da série se recusam a se engajar em prazeres ilícitos ou imorais, elas ganham a possibilidade de não serem pegas de surpresa, ao contrário das outras personagens da série.

A Morte, por não ter corpo, não possui fraquezas físicas e não pode ser enfrentada diretamente, mas, na melhor das hipóteses, esquivada por um tempo mais ou menos limitado: segundo o herói da diegese, Alex Browning, "Eu posso derrotar você! Não para sempre...". Tais limitações físicas tornariam o filme desinteressante para o espectador, dada a impossibilidade absoluta de vitória (mesmo parcial), não fosse uma compensação na forma de premonições que Alex tem, que o ajudam a prever de que forma a Morte agirá. Alex passa a ver os desígnios do sistema operante da Morte em cada detalhe de seu cotidiano, em um recorte de jornal, um reflexo, uma ilusão, etc.

Ironicamente, a adaptabilidade da Morte perante o descobrimento de seus sinais iguala-se à do sistema capitalista, que, ao ser descoberto em suas estratégias de controle, reelabora-se para dificultar esse mapeamento e eventual afrontamento. No filme, as dicas do que vai acontecer são muito mais numerosas na primeira sequência, do aeroporto, quando pululam expressões como terminal, departed, final destination ${ }^{8}$, expediente diminuído após a constatação de que tais dicas podem realmente salvar a vidas das pessoas envolvidas. Chega-se, nesse ponto, à personagem responsável por advertir o grupo do perigo que correm e como evitá-lo: nos filmes da leva anterior, há sempre uma figura menor na narrativa encarregada de alertar o grupo do risco iminente ${ }^{9}$. Em Sexta-feira 13, esse papel é desempenhado pelo velho da comunidade próxima ao acampamento, prontamente taxado de louco por seus pares e desconsiderado pelos jovens; por outro lado, o conhecimento prévio de Browning não apenas não pode ser desconsiderado, mas seu vaticínio passa a ser visto como algo a ser temido, inicialmente por tomá-lo por principal suspeito na explosão do avião e, depois de provada a falha mecânica na nave e, consequentemente, sua inocência, ainda assim ele continua a ser temido como alguém fora do normal.

$\mathrm{O}$ último ponto de exploração no cotejo dos dois monstros diz respeito às armas que cada um usa para matar suas vítimas. Jason, como uma personificação alegórica da lei social, utiliza uma série de símbolos fálicos para seus assassinatos, incluindo facas, tesouras, lanças, arpões e todo tipo de objeto pontiagudo, sempre penetrando e feminilizando a vítima, submetendo-a a essa lei. Por outro lado, temos em Premonição

\footnotetext{
8 Departed, no contexto de aeroportos, significa que o voo decolou, mas, em outro contexto, pode significar falecido (aqueles que se foram, que partiram); Final destination, destino final, é o nome do filme em inglês, o que aplica um sentimento muito mais derrotista que Premonição, aspecto positivo que permite aos personagens o escape.

${ }^{9}$ Como aponta Dika (1987, p. 94) em sua estruturação dos enredos de filmes do gênero.
} 
um dos maiores argumentos de identificação entre a Morte e as forças do capital: esse monstro sempre se utiliza de falhas nos objetos de consumo, produzidos justamente a partir da instrumentalização da ciência para o incremento do consumismo capitalista. Neste caso, opera-se a lógica em que a ausência traduz-se na melhor confirmação da presença, pois a Morte, controlando os corpos, poderia causar falecimentos por motivos naturais, como doenças, mas isso nunca acontece; defeitos em objetos do cotidiano são sempre responsáveis pelos acidentes que resultam nas mortes das personagens, ou seja, o avião explode por um mau funcionamento da bomba de combustível, uma caneca racha e despeja vodka num monitor de computador, uma torneira vaza e provoca um escorregão, etc. Dialeticamente, as maiores conquistas em termos de conforto para os sujeitos do sistema (o encurtamento das distâncias com viagens rápidas e confortáveis, as comodidades da eletro-informática, a água encanada, etc) não apenas confinam os indivíduos a uma condição de escravidão e não escape ao mundo administrado, mas também funcionam como mecanismos responsáveis pela morte das pessoas.

Pode-se pensar em um moralismo controlador em ambos os filmes. A série Sextafeira 13 pauta-se em uma mensagem óbvia de "não se engajem em prazeres e esqueçam suas responsabilidades", comumente identificada nos contos infantis e fábulas, tencionando um controle ético dos corpos de seus espectadores, especialmente através de um monstro cuja vigilância é incansável ${ }^{10}$. Em Premonição, por outro lado, o controle moralista estrutura-se de forma mais dissimulada, pois, ao propagar a impossibilidade de luta, deixando como alternativa somente escapes temporários, o filme prega uma ideologia de conformidade e sujeição, onde cabe, no máximo, culpar o sistema pelas mazelas que serão infligidas.

Quanto a essas reações de enfrentamento das personagens nos dois filmes, três delas são comuns: a negação, a desqualificação dos analistas e, até certo ponto, a fuga. A negação figura como a reação mais comum perante qualquer evento inacreditável, e isso acontece em ambos os filmes, notadamente quando o aviso de perigo (o mapeamento do sistema) é dado (feito) por uma pessoa com qualificações duvidosas: na série Sexta-feira 13, o aviso é emitido por um velho considerado louco, automaticamente desqualificado e ridicularizado; em Premonição, o adolescente que antecipa o acidente com o avião passa a ser considerado uma ameaça e subsequente aberração. Dessa forma, sua visão ampla e não compartilhada por todos os membros da comunidade assume o lugar do verdadeiro antagonista para várias personagens, no estilo do horror americano em que o dom é dialetizado com traços simultâneos de maravilha e maldição, como, por exemplo, em várias obras de Stephen King, de $O$ iluminado a $A$ hora da Zona Morta.

A fuga é usada pelas personagens de ambos os filmes, mas de forma diferente. As vítimas de Sexta-feira 13 tentam fugir e são impedidas pelo monstro, pois, ao saírem daquele espaço (um acampamento no meio da floresta), elas estariam livres da ameaça. As personagens de Premonição não possuem esse subterfúgio num mundo pósindustrial: dada a homogeneidade e a planificação dos espaços, a fuga é meramente temporária, e, quando escapam da sociedade consumista, chegam a ambientes similares.

\footnotetext{
${ }^{10}$ Sobre o sistema de controle e vigilância dos corpos pelo capital, ver Foucault (1987).
} 
Browning, por exemplo, encontra refúgio em uma cabana rural, não muito diferente das que apareceriam na outra série; contudo, depara-se não com um mundo seguro préindustrial, mas antes um depósito abarrotado de produtos de consumo descartados, potencialmente tão perigosos quanto os do mundo externo, corroborando a tese de que não pode haver escapatória ou alternativas para o mundo capitalista.

Em termos de enfrentamento, as personagens de Sexta-feira 13 têm a opção de lutar fisicamente com Jason, devido ao fato de ele ter um corpo material, mesmo que ele não possa ser derrotado a não ser em um plano ético; em Premonição, por outro lado, as personagens almejam mais uma resolução com elas mesmas, geralmente ligadas à aceitação ou não dos mapeamentos, ou ainda, em termos de ações concretas, atitudes que englobem a desistência ou, na melhor das hipóteses, o esquivamento. Isso é bastante significativo porque se fundamenta em dois princípios: primeiro, a esfera subjetiva teria um papel preponderante na determinação das reações em Premonição, enquanto os seres de Sexta-feira 13 agiriam mais ou menos de acordo com valores absolutos e, em princípio, sem margem a questionamentos relativizadores ou dialetizantes; e, segundo, enquanto Jason poderia ser derrotado por completo devido à sua limitação corpórea que faz dele um ser circunscrito a um tempo e espaço definidos, a vitória sobre a Morte não se configura apenas como um dado impossível diante de sua imaterialidade, mas, sobretudo, porque sua atuação está intrinsecamente atrelada à lógica operante do sistema capitalista.

Por essa razão, resta pouco às personagens de Premonição a não ser lidar com a aceitação da inevitabilidade, geralmente desembocando em dois tipos de reações: a tentativa de controlar sua morte ou a de fugir pela maior quantidade de tempo possível. Para aqueles que negam sua própria impotência, após a impossibilidade de desqualificação dos analistas, a atitude mais comum é a tentativa de provocar sua morte, tentando o suicídio. A cena mais característica nesse âmbito apresenta o inconformismo de Carter Horton (Kerr Smith), após perder a namorada Terry Chaney (Amanda Detmer): com todas as pessoas perseguidas pela Morte no carro, ele acelera demasiadamente e dirige imprudentemente, arriscando matar a todos, de forma que ele possa escolher a forma e o momento que vai morrer e, assim, derrotar seu inimigo. Como isso não acontece, e apesar do carro quase colidir com outros, é somente após parar o carro e os outros saírem que ele corre real perigo de morte, mas é salvo por Alex.

No outro fim do espectro, o da conformidade, as personagens aceitam sua morte e caminham para ela, a exemplo de Alex no desfecho do filme. Ao perceber que a Morte voltou por ele mais uma vez, o protagonista pede que a namorada Clear Waters (Ali Larter) não o acompanhe, e é salvo por Carter. Assim, pontuamos o último fator importante para nossa discussão, o de que, em geral, não há maneira individual de adiar a morte; ela tem que vir de uma fonte externa, seja na forma ora de uma visão/premonição, ora de uma ajuda física que afasta a pessoa do perigo iminente.

Dessa maneira, chegamos ao paralelo mais significativo entre o capitalismo de Fukuyama e a Morte de Premonição, o qual mostra a adaptabilidade do gótico ao seu momento de produção: ambos estruturam-se na premissa de que não há exterioridade ou fuga possível, apenas uma procrastinação temporária. A tentativa de escapar de 
qualquer um deles é sempre frustrada pela evidente falta de alternativa e pela naturalidade com a qual essa inevitabilidade é aceita pelos sujeitos sem grandes resistências, fomentando assim uma perigosa ideologia de inutilidade das estratégias de resistência.

\section{CONCLUSÃO}

Em termos de conclusão, primeiramente, o monstro de Premonição não pode ser derrotado nem combatido, somente esquivado, ao contrário da redenção parcial das vítimas de Sexta-feira 13, confirmando, assim, a metáfora do capitalismo neoliberal de Fukuyama que engloba a todos sem distinção. Segundo, a construção dessa recente figura do monstro abandona o emprego de planos subjetivos, como se fazia na década de 1980, atuando através de elementos naturais, como vento e sombra, ou dos reflexos em bens de consumo. As armas de que faz uso, constituídas de falhas em objetos industrializados, substituíram as armas cortantes da década de 1980, reforçando assim a relação com o sistema de produção e consumo desenfreados, portanto assinalando o status de ubiquidade e naturalidade alcançados por esse sistema na ordem mundial contemporânea. Finalmente, os discursos das personagens acossadas pela Morte constituem uma metáfora subjacente à ideologia do sistema, revelando uma miríade de possibilidades falidas, desde a simples negação infundada, passando pela desqualificação daqueles que conseguem mapear o sistema estabelecido. O resultado mais evidente dessa estruturação discursiva encontra seu paroxismo na aceitação como única forma de solução. Apesar de se observar que este mesmo discurso seja pontuado por momentos em que formas (pífias) de resistência são possíveis, ao menos no entendimento das personagens. Isto é, a desistência desesperada, ou a luta por um adiamento do que já é tomado por uma inevitabilidade, particularmente por estar condicionado à interferência de uma força externa, conformam-se sempre a uma ideologia de passividade em relação às vítimas.

Todos esses sintomas descritos na diegese fílmica configuram-se como modificações sutis, porém interessantes, na maquinação do gótico de uma década para outra, dialogando com a produção discursiva de seu tempo. Como se pode observar, o antagonismo engendrado na divisão do mundo em dois blocos durante a Guerra Fria, algo reconfortante para as populações que vivem sob a ameaça de um antagonista, juntamente com a lógica de controle que imperou até o final da década de 1980, cedem lugar a certa caoticidade cuja mais sintomática característica está no esforço em desqualificar ou mesmo eliminar de maneira acachapante qualquer ameaça que denuncie as semelhanças ideológicas entre um sistema único, ou um modelo econômico sem alternativas, uma ditadura.

Com efeito, como uma modificação nas bases de estruturação e operação de um sistema desse porte não passaria incólume, nota-se que uma nova forma de recalque emerge nessa mudança. Antes, quando o antagonismo era concreto, os indivíduos que falavam contra o sistema eram simplesmente desconsiderados, tidos como loucos ou imaturos. Nessa nova ordem destituída de uma materialidade opositora, qualquer sujeito que confronte diretamente a ordem vigente passa a ser visto como potencialmente 
perigoso. A partir de uma abordagem mais maniqueísta, pode-se dizer que a melhor maneira de desviar a atenção para os problemas internos de um sistema único é a de criar alguma forma de oposição clara, mesmo fraca, como é o caso, simulando a ameaça não mais existente.

A discussão dos recalques na narrativa também nos fornece subsídios para voltarmos à questão do hibridismo nos dois monstros, particularmente no que concerne à dimensão final do quanto esses eventos realmente promoveram tais modificações acima descritas. $\mathrm{O}$ recalque do tipo de compreensão de seu mundo aparece exatamente na formação constitutiva do ser abjeto, de modo que este é composto pelo oposto estranho (no sentido freudiano de Unheimlich) daquilo que a representação social escasseia. Durante toda a década de 1980, o gótico, espelhando um mundo em que a polarização configurou-se como regra, ao mesmo tempo em que a unicidade das instituições capitalistas implicava em proteção contra o sistema ameaçador comunista; logo, nada parece ser mais natural que uma ameaça híbrida, de carne e osso, mas também imortal, até certo ponto conciliando os dois extremos de vida e morte (ou, na metáfora, capitalismo e comunismo, não necessariamente nessa ordem). Por outro lado, para a década seguinte, em que a polarização havia sido destruída e o capitalismo emergia como modelo exclusivo de organização política e, simultaneamente, como antagonista exclusivo contra o qual lutar, fazendo essa década explodir com discursos de hibridização em favor das minorias, nada mais sintomático e revelador que o ser estranho desse período certamente apresentar-se como uno ${ }^{11}$, pertencente exclusivamente ao universo das mercadorias e bens de consumo produzidos pelo mundo pós-industrial.

\section{REFERÊNCIAS}

ADORNO, T. W. Adorno: the stars down to Earth and other essays on the irrational in culture. London: Routledge, 1994.

; HORKHEIMER, M. Dialética do esclarecimento. Rio de Janeiro: Jorge Zahar, 1985.

ANDERSON, P. O fim da história: de Hegel a Fukuyama. Rio de Janeiro: Jorge Zahar, 1992.

BAUMAN, Z. Vida para consumo: a transformação das pessoas em mercadoria. Rio de Janeiro: Jorge Zahar, 2008.

BRANIGAN, E. Point of view in the cinema. Berlin: Mouton, 1984.

CLOVER, C. Men, women and chainsaws: gender in the modern horror film. Princeton: Princeton University Press, 1992.

DIKA, V. The stalker film, 1978-81. In: WALLER, G. A. (ed.). American horrors: essays on the modern American horror film. Urbana: University of Illinois Press, 1987. p. 86-101.

FOUCAULT, M. Vigiar e punir: o nascimento da prisão. 25. ed. Petrópolis: Vozes, 1987. fontes, 2008.

Nascimento da biopolítica: curso dado no Collège de France (1978-1979). São Paulo: Martins

FRIEDMAN, T. L. O mundo é plano: uma breve história do século XXI. Ed. Revista e atualizada. Rio de Janeiro: Objetiva, 2007.

FUKUYAMA, F. O fim da história e o último homem. Rio de Janeiro: Rocco, 1992.

JAMESON, F. Postmodernism or The cultural logic of late capitalism. Durham: Duke University Press, 1991.

\footnotetext{
${ }^{11}$ O oposto se dá, por exemplo, na trilogia Pânico (1996; 1998; 2000), dirigida por Wes Craven, em que o assassino, aparentemente imortal, revela-se somente uma pessoa com um colete à prova de balas.
} 
Recebido em 05/04/2015. Aprovado em 17/05/2015.

Title: Death comes to all: intensification of capitalism in the late twentieth century

Abstract: The objective of this work is to discuss the discursive modification spawned in the beginning of the 1990's, after the breakup of the communist bloc and the rise of apologies defending the capitalistic victory, starting from the transformation occurred in the forms of representation concerning filmic monsters. For doing so, the apologetic discourse towards capitalism by Francis Fukuyama (1992) is presented, with the purpose of balancing the composition of Jason Vorhees, from the Friday the 13th series (1981; 1982; 1984), against Death in Final destination (2000), and how they also affect their victims' reactions. The main conclusion in this text is that, at the end of the analysis, the ubiquity, naturalness and inevitability of the 1990's assassin present themselves in consonance with the victory of capital as professed by Fukuyama, signaling off an exaggerated forfeiting.

Keywords: Slasher movies. Critical theory. Capitalism. 